\title{
Exergy Analysis of Liquid Nitrogen Power Cycles
}

\author{
Pawet Wojcieszak ${ }^{1, *}$ \\ ${ }^{1}$ Wroclaw University of Science and Technology, Department of Cryogenic, Aeronautic and Process \\ Engineering, Wyb. Wyspianskiego 27, 50-370 Wroclaw, Poland
}

\begin{abstract}
Nitrogen is by-product from cryogenic air separation processes used for oxygen production for metallurgy and oxygen-enriched combustion purposes. If the gases are delivered from air separation unit (ASU) in liquid phase, liquid nitrogen $\left(L N_{2}\right)$ can be used as energy accumulator for stabilization of electrical grid system with large share of renewable energy sources. When the energy demand is high and not enough electricity is generated in power plants, energy accumulated in $L N_{2}$ may be recovered in a cryogenic power cycle. In this research complete exergy analysis of liquid nitrogen direct expansion cycle and combined direct expansion/Brayton cycle was performed.
\end{abstract}

\section{Introduction}

Oxygen is used on large scale in metallurgy since the beginning of 20th century. In recent years also the use of oxygen in power generation is investigated. Oxy-combustion is one of promising technologies for reduction of $\mathrm{CO}_{2}$ emissions, in this technology pure oxygen is provided to boilers instead of air [1]. The most mature technology of oxygen production is cryogenic air separation. Nitrogen is by-product of this process. It is possible to use nitrogen as energy accumulator, if air ingredients are collected from the air separation unit (ASU) in liquid form. The principle of nitrogen based energy storage system operation was shown on figure 1 . When the demand for electricity is low, the energy can be used for air separation and

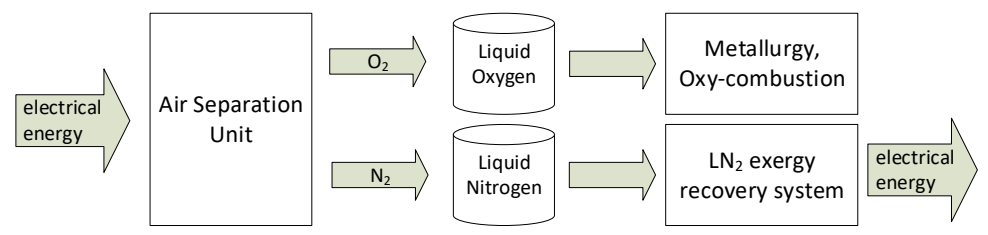

Figure 1. Principle of $L N_{2}$ based energy storage system operation.

liquefaction. Oxygen can be used for industrial and power generation purposes, while liquid nitrogen can be stored in cryogenic vessel. When the demand for electrical energy is high, stored liquid nitrogen can be expanded in $L N_{2}$ exergy recovery system to produce electricity. Two configurations of such systems were analyzed in this paper.

\footnotetext{
*e-mail: pawel.wojcieszak@pwr.edu.pl
} 


\section{Exergy recovery systems analysis}

Exergy is the amount of useful work that can be obtained from a system by bringing it to thermodynamic equilibrium with its surroundings. As a cryogenic fluid with temperature much lower than ambient, $L N_{2}$ has large exergy. Specific physical exergy of liquid nitrogen can be expressed as follows [3]:

$$
e_{L N_{2}}=h-h_{0}-T_{0}\left(s-s_{0}\right)
$$

where: $h_{0}, s_{0}$ - specific enthalpy and entropy at ambient conditions (temperature and pressure). Specific exergy of liquid nitrogen at $1 \mathrm{bar}$ is equal to $769 \mathrm{~kJ} / \mathrm{kg}$ and exergy density (exergy per unit volume) $-620 \mathrm{~kJ} / \mathrm{m}^{3}$.

\subsection{Direct expansion cycle}

One of the simplest systems for recovery of liquid nitrogen exergy is direct expansion cycle (figure 2). Liquid nitrogen from cryogenic vessel is pumped (1-2) to high pressure, then it is heated in HX1 (2-3) using ambient as a heat source. Then it is expanded in 2 stage expander (3-4 and 5-6) with reheating in HX2 (4-5). After expansion the nitrogen is heated (6-7) and released to atmosphere.

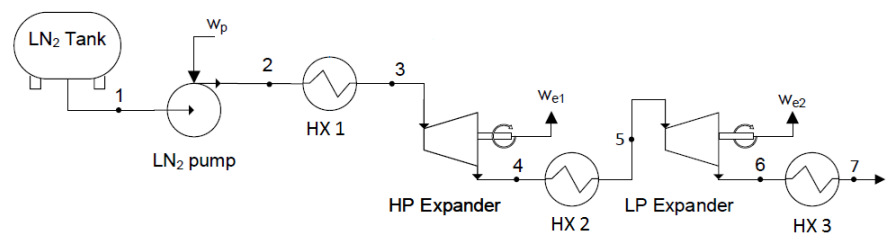

Figure 2. Scheme of 2-stage direct expansion $L N_{2}$ exergy recovery system.

Exergetic efficiency of a system was defined as a ratio of useful exergy extracted from the system to exergy input [4]:

$$
\eta_{e}=\frac{w_{\text {out }}}{e_{\text {in }}}
$$

The exergetic efficiency $\eta_{e D E}$ of the direct expansion system is defined as the ratio between the expander work $w_{e}$ and the sum of the LNG exergy $e_{1}$ and the pump work $w_{p}$ :

$$
\eta_{e D E}=\frac{w_{e 1}+w_{e 2}}{e_{1}+w_{p}}
$$

Main parameters of analyzed direct expansion cycle are shown in table 1. Exergetic efficiency and net work of the cycle were calculated, using open-source thermodynamic properties library Coolprop [2] for different pump pressures. Results are shown in figure 3.

An important issue in the optimization of the discussed systems is determining which component us responsible for the main loss of exergy. Exergy destruction in the $L N_{2}$ pump $\Delta e_{p}$ can be calculated using formula:

$$
\Delta e_{p}=\left(e_{1}-e_{2}\right)-w_{p}
$$

Exergy destruction in heat exchanger heated using ambient (ex. $\left.\Delta e_{H X 1}\right)$ can be determined as the difference of outlet and inlet streams exergy: 
Table 1. Direct expansion cycle parameters

\begin{tabular}{ll}
\hline Parameter & Value \\
\hline Ambient temperature & $300 \mathrm{~K}$ \\
Ambient pressure & $1 \mathrm{bar}$ \\
$L N_{2}$ pressure & $1 \mathrm{bar}$
\end{tabular}

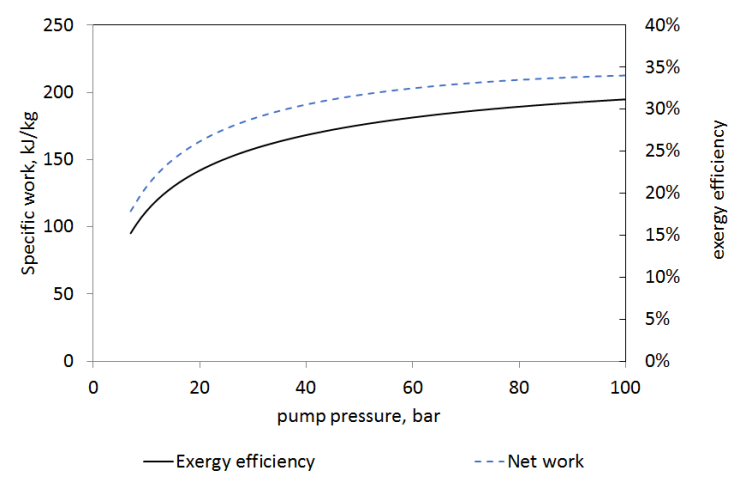

Figure 3. Exergy efficiency and specific work of 2-stage direct expansion system as a function of pump pressure.

$$
\Delta e_{H X 1}=e_{2}-e_{3}
$$

Finally, exergy loss in the expander is:

$$
\Delta e_{e}=\left(e_{3}-e_{4}\right)-w_{e} .
$$

The losses in direct expansion system operating for 100 bar pump pressure are shown on figure 4. It might be noticed that the largest exergy loss occurs in HX1. It is because nitrogen after pump has still very low temperature and therefore large exergy, which is destroyed in heat transfer process with ambient. That is why the combined cycle (figure 5) was proposed. In this case, cold high pressure nitrogen is used for cooling down the gas in Brayton cycle operating between ambient temperature and pressurized nitrogen temperature. Nitrogen-based Brayton cycle was selected to match the temperature profile of nitrogen in the HX1 (on figure 5) and reduce exergy loss in that heat exchanger.

\subsection{Combined direct expansion + Brayton cycle}

The work principle is the same as in the case of the direct expansion cycle described above, but with the addition of Brayton cycle. Working fluid of Brayton cycle is cooled down in HX1 (1B-2B), then compressed in compressor (2B-3B), warmed up to ambient temperature in HX5 (3B-4B) and then expanded (4B-5B and 6B-1B) in two stage turbine with reheating in HX6 (5B-6B). Parameters of the cycle are presented in table 2. Net power generated in Brayton cycle was calculated for different compressor discharge pressures. The optimal discharge pressure is 5.6bar (figure 6). Exergy efficiency was obtained using formula:

$$
\eta_{e C o m b}=\frac{W_{e 1}+W_{e 2}+W_{e 3}+W_{e 4}}{E_{1}+W_{p}+W_{c}} .
$$




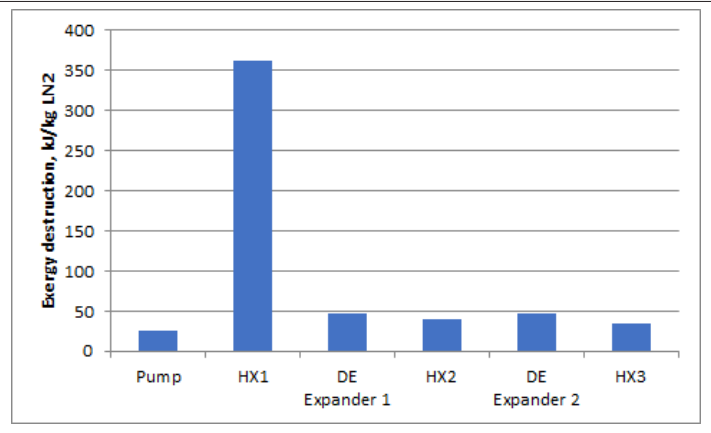

Figure 4. Exergy losses in direct expansion system (for 100 bar pump pressure).

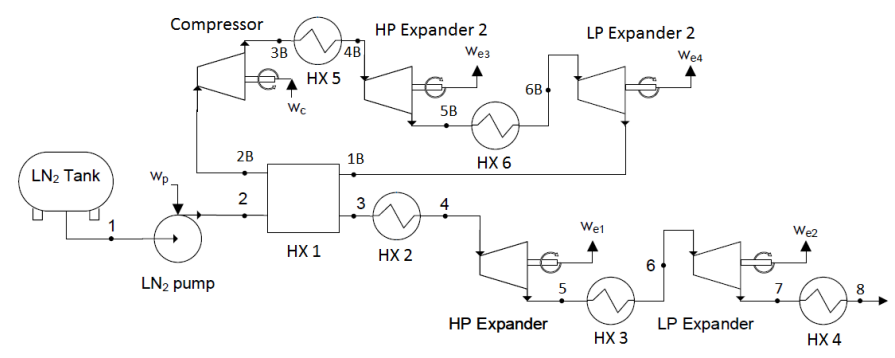

Figure 5. Scheme of combined direct expansion/Brayton cycle $L N_{2}$ exergy recovery system.

Table 2. Combined cycle parameters

\begin{tabular}{ll}
\hline Parameter & Value \\
\hline Ambient temperature & $300 \mathrm{~K}$ \\
Ambient pressure & $1 \mathrm{bar}$ \\
Direct expansion pump pressure & $100 \mathrm{bar}$ \\
Direct expansion mass flow & $1 \mathrm{~kg} / \mathrm{s}$ \\
$L N_{2}$ pressure & $1 \mathrm{bar}$ \\
Brayton cycle low pressure & $1.1 \mathrm{bar}$ \\
Brayton cycle working fluid & nitrogen
\end{tabular}

For the considered system (pump pressure - 100 bar, compressor discharge pressure - 5.6 bar) exergy efficiency was equal to $36 \%$ (for the previous cycle with the same parameters, exergy efficiency was $31.1 \%$ - see figure 3 ).

Exergy destruction in all of the components was determined using equations 4,5,6 compressor is calculated the same way as for pump (eq. 4). Exergy destruction in heat exchanger HX was obtained using formula:

$$
\Delta E_{H X 1}=\left(E_{2}-E_{3}\right)-\left(E_{1 B}-E_{2 B}\right) .
$$

The exergy losses in all of the components are shown in figure 7. The losses in heat exchange process are significantly lower than in direct expansion cycle, however there are additional losses in Brayton cycle expanders and compressor. 


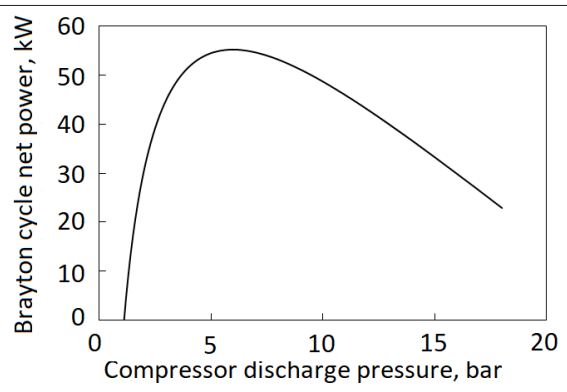

Figure 6. Net power generated in Brayton cycle as a function of compressor discharge pressure.

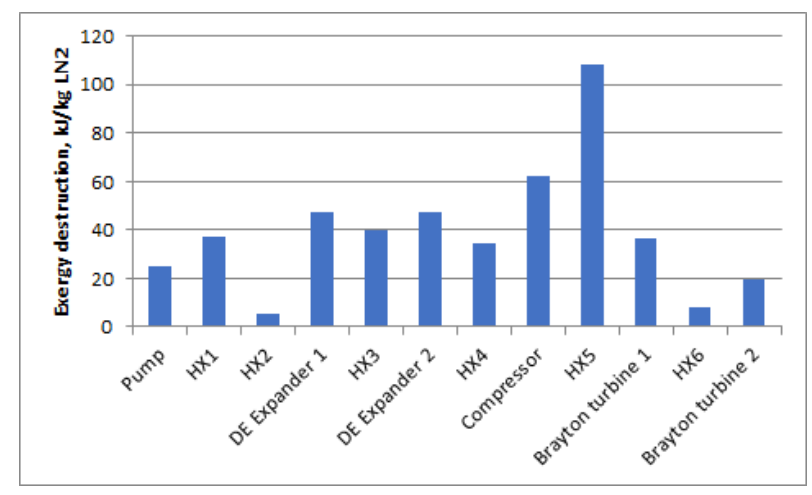

Figure 7. Exergy losses in combined system (for 100 bar pump pressure and 5.6 bar compressor discharge pressure).

\section{Conclusions}

Two simple cycles for liquid nitrogen exergy recovery were analysed. Exergy losses in combined system are lower than in the direct expansion system and also the exergetic efficiency of combined cycle is higher. If there are waste heat sources available, the efficiency of both Brayton cycle and direct expansion cycle can be further increased by increasing the temperature of gas before the expander. Overall efficiency of process can be also improved by using the cold working fluid as a source of cooling power for refrigerated warehouse or air conditioning.

The presented works were co-financed from statutory funds granted by Polish Ministry for Science and Higher Education.

\section{References}

[1] M. Chorowski, W. Gizicki, Archives of Thermodynamics 36 (2015)

[2] I.H. Bell, J. Wronski, S. Quoilin, V. Lemort, Industrial \& Engineering Chemistry Research 53, 2498 (2014)

[3] J. Szargut, Exergy method: technical and ecological applications, Number 18 in International series on developments in heat transfer (WIT Press, Southampton ; Boston, 2005), ISBN 978-1-85312-753-3, oCLC: ocm56874184

[4] P. Dorosz, P. Wojcieszak, Z. Malecha, Entropy 20 (2018) 